\title{
Low-temperature organic Rankine cycle engine with isothermal expansion for use in desalination
}

\author{
Opubo N. Igobo, Philip A. Davies \\ Sustainable Environment Research Group, School of Engineering and Applied Science, Aston University, \\ Birmingham, B4 7ET, UK email: p.a.davies@aston.ac.uk
}

\begin{abstract}
Ground water salinity is a widespread problem that contributes to the fresh water deficit of humanity. Consequently, where conventional energy supply is also lacking, organic Rankine cycle (ORC) engines are being considered as a feasible option to harness readily available low-grade heat (< $180^{\circ} \mathrm{C}$ ) to drive the desalination of the saline water via reverse osmosis (RO). However, this application is still not very well developed, and has significantly high specific energy consumption (SEC). Hence, this study explores the isothermal expansion of the ORC working fluid to achieve improved efficiency for driving a batch-RO desalination process, 'DesaLink'. Here the working fluid is directly vaporized in the expansion cylinder which is heated externally by heat transfer fluid, thus obviating the need for a separate external boiler and high pressure piping. Experimental investigations with R245fa have shown cycle efficiency of $8.8 \%$. And it is predicted that the engine could drive DesaLink to produce 256 litres of fresh water per 8 hour per day, from $4000 \mathrm{ppm}$ saline water, with a thermal and mechanical SEC of $2.5 \mathrm{kWh} / \mathrm{m}^{3}$ and $0.36 \mathrm{kWh} / \mathrm{m}^{3}$ respectively, representing a significant improvement on previously reported or predicted SEC values.
\end{abstract}

Keywords

Energy and water

Low-grade heat

Organic Rankine cycle

Isothermal expansion

Desalination 


\section{Introduction}

About 768 million people in the world lack improved (safe) drinking water [1]. Groundwater salinity contributes to the fresh water shortfall, and also affects agricultural yields. It is a widespread problem, occurring in all the inhabited continents of the world, especially the arid and semi-arid regions [2]. Where the regions lack access to conventional energy supply (and the cost of connecting is prohibitive), sustainable and renewable energy sources (RES) such as solar, wind, geothermal, biomass, and waste heat recovery can be harvested to power desalination of the saline water.

Over the years, there have been a number studies on alternative energy (especially solar) driven desalination technologies [4]. Reverse osmosis (RO) technique is increasingly gaining popularity over thermal distillation, as it is considered more energy efficient, due to its relatively lower specific energy consumption (SEC) [5]. RO desalination is a mechanical separation technique which involves the application of pressure to saline water against a semipermeable membrane, such that water is forced through the membrane as permeate, leaving behind the salt particles as concentrate. For most of the installed solar RO desalination plants, the energy required to produce the pressure is generated from solar photovoltaic (PV) array [6,7] (whose electrical output is converted to mechanical energy); but cost and low efficiency of scale tend to be drawbacks of this technology.

Nevertheless, as reported in literatures, solar thermal power cycle - such as the organic Rankine cycle (ORC) - can also be used to produce the required mechanical work directly (without the electrical to mechanical energy conversion process associated with the solar PV method, thus avoiding the inherent losses associated with the conversion process). Manolakos et al. [8] reported an experimental ORC-RO desalination system that produced $2.55 \mathrm{~m}^{3}$ (per 9 hours) of fresh water from sea water, at a recovery ratio of $21 \%$, and with a SEC of $2.3 \mathrm{kWh} / \mathrm{m}^{3}(8.28 \mathrm{~kJ} /$ litre $)$ and thermal cycle efficiency of $1.17 \%$; although a system efficiency of $7 \%$ was initially predicted in the design study [9]. Bruno et al [10] carried out a design study and presented ORC mechanical power requirement of $11.7 \mathrm{~kW}$ for a desalting capacity of $15 \mathrm{~m}^{3}$ per $7 \mathrm{~h}$ day from 3000 ppm brackish water - thus implying a SEC of 0.78 $\mathrm{kWh} / \mathrm{m}^{3}$ (2.81 $\mathrm{kJ} /$ /itre). Although these systems are not yet very well developed [11], they are particularly attractive when heat is available as a by-product from solar or other processes.

Ideally, in the desalination of groundwater, high recovery ratio would be preferred, so as to maximize fresh water output and minimize the volume of concentrated brine rejected, since the disposal could pose an environmental problem. However, high recovery ratio tends to require high energy inputs due to the increase in osmotic pressure as a result of the concentration increase with water removal at the RO module outlet. The conventional method of continuous flow operation suffers from this high energy requirement or otherwise low recovery ratio. But in contrast, in a batch operation, concentration is kept almost uniform through the system at each moment in time, thus minimizing the energy requirement due to concentration increase [4].

Davies [4] proposed a batch desalination system (DesaLink) in which a linkage mechanism with increasing mechanical advantage was proposed to utilize steam pressure to drive the desalination process in batches. The device was designed to yield high recovery of fresh water at low specific energy consumption. Qiu et al [12] developed a prototype of the DesaLink driven by compressed air instead of steam. Preliminary experiments with the DesaLink showed recovery ratio of $70 \%$. The 
system required a starting driving force of $28 \mathrm{kN}$ for a $200 \mathrm{~mm}$ bore power cylinder and a cycle time of about 4 minutes. Igobo and Davies [13] reported a water/steam Rankine cycle power cylinder with isothermal expansion operated at cylinder wall temperature of $240^{\circ} \mathrm{C}$; the study indicated output force of up to $13 \mathrm{kN}$ for $100 \mathrm{~mm}$ bore cylinder, and it was concluded that the isothermal Rankine cycle engine can be easily scaled-up to drive DesaLink. The isothermal expansion was preferred over the conventional adiabatic (isentropic) expansion for higher thermal efficiency.

However, when the temperature level of the available heat source is not sufficient for the steam cycle, organic working fluid becomes an alternative. Thus, this paper aims to assess the potential performance of the isothermal ORC engine when employed to drive the DesaLink for low temperature $\left(<120^{\circ} \mathrm{C}\right)$ heat sources. To achieve this, the performance of the engine will be modelled and various working fluids will be analysed to select the potential fluid(s); experimental work with a potential fluid will be carried out to ascertain its real performance. And finally the integration of the isothermal ORC to DesaLink will be investigated.

\section{Description of the reciprocating heat engine}

Figure 1 depicts the schematics of the isothermal reciprocating engine. The processes that occur within one cycle of operation in the cylinder, $\mathrm{C}$, are as follows:

- Injection (C1-C2): During the injection process, the intake valve opens, and the metering pump injects a volume (with mass $m$ ) of pressurized working fluid into the cylinder.

- Vaporization (C2-C3): The liquid is heated and vaporized by the hot cylinder wall to become dry saturated vapour, with pressure $\mathrm{P}_{\mathrm{C} 3}$. In this process, the vapour performs some work, since the volume of the vapour is greater than that of the liquid.

- Expansion (C3-C4): The vapour expands and performs further work against the piston. Due to continuous heat transfer from the cylinder wall, the vapour is superheated, as the expansion proceeds isothermally to pressure $\mathrm{P}_{\mathrm{C} 4}$ at the end of stroke.

- Blow down (C4-C5): At the end of stroke, the exhaust valve is opened and some of the vapour blows down (through a regenerator, if employed) into the condenser and the vapour's pressure $\left(\mathrm{P}_{\mathrm{C} 4}\right)$ is reduced to the condenser Pressure $\left(\mathrm{P}_{\mathrm{C} 5}\right)$.

- Exhaust (C5-C1): On the return stroke, the piston displaces the remaining vapour through the regenerator (if employed) into the condenser, until piston gets back to the cylinder head, and then the valve is closed in preparation for the next cycle. 


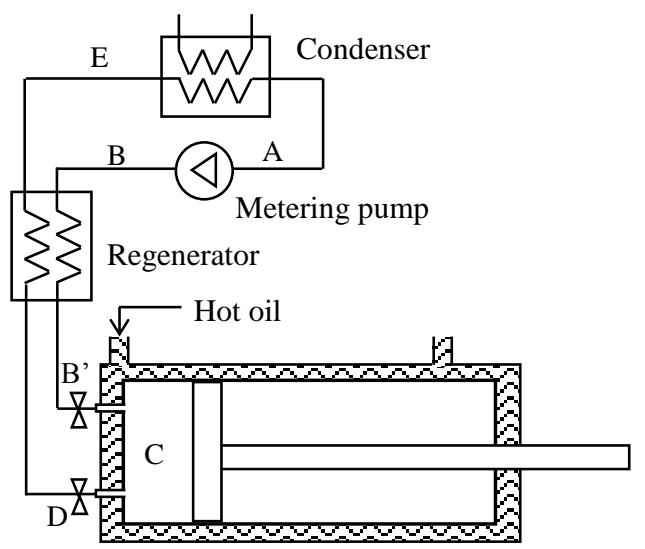

(a)

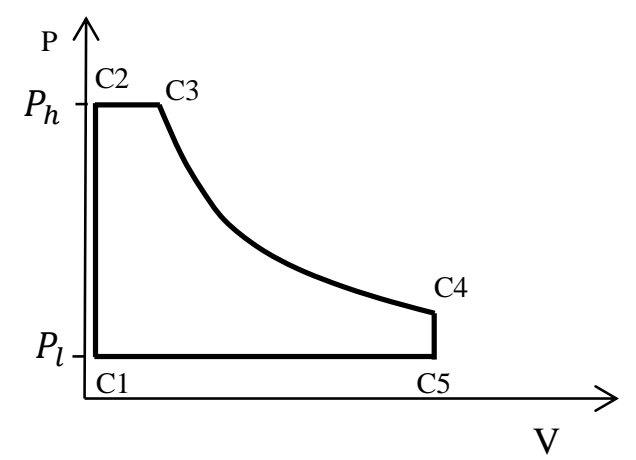

(c)

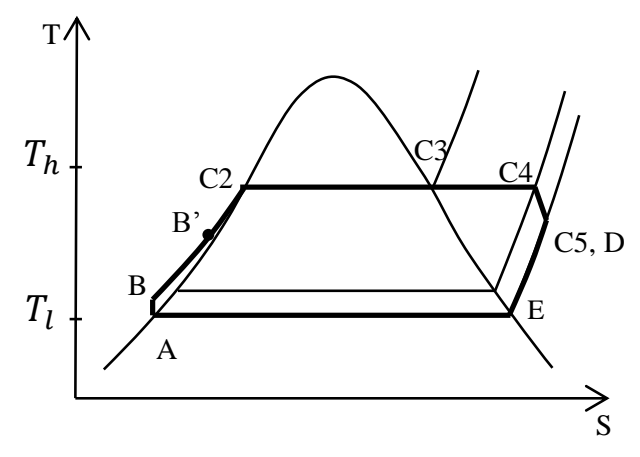

(b)

Fig. 1 (a) the system schematic (b) T-s diagram showing states in the system at different positions in the system $\mathrm{A}-\mathrm{E}$ and times $\mathrm{C} 1-\mathrm{C} 5$ (c) P-V diagram showing states in the cylinder (position $\mathrm{C}$ ) at different moments in time during the cycle $(1-5)$

\subsection{System analysis}

The working process of the systems within one cycle of operation could be modelled with a set of appropriate non-flow analysis. However, it can be assumed that the mass of fluid in the regenerator and condenser is much larger than in the cylinder, therefore the flows and pressure in the condenser are effectively steady over time; thus flow analysis can be approximated here. The analysis is carried on the basis of mass ' $m$ ' of working fluid corresponding to one cycle of the engine.

The work input by the pump in injecting the working fluid into the cylinder entails the work required to pressurize the liquid. Thus the pump work can be obtained as:

$$
W_{A B}=m v_{f l}\left(P_{h}-P_{l}\right)
$$

Where, $P_{h}$ and $P_{l}$ are the upper and lower pressures of the cycle corresponding to saturation temperatures $T_{h}$ and $T_{l}$ respectively; while $v_{f l}$ is the specific volume of the saturated liquid at $P_{l}$.

The heat input required to heat and vaporize the fluid is given by:

$$
Q_{B C 3}=m\left[C_{p f}\left(T_{h}-T_{l}\right)+T_{h}\left(s_{C 3}-s_{C 2}\right)\right] \approx m\left(h_{C 3}-h_{B}\right)
$$


The work output during the vaporization phase can be given as:

$$
W_{C 23}=m P_{h}\left(v_{g}-v_{f}\right)
$$

The heat input required to achieve isothermal expansion of the superheated vapour can be given as:

$$
Q_{C 34}=m T_{h}\left(s_{C 4}-s_{C 3}\right)
$$

And the expansion work output can be given as:

$$
W_{C 34}=Q_{C 34}-m\left(u_{C 4}-u_{C 3}\right)
$$

The work input during the return stroke to exhaust the vapour can be given as:

$$
W_{C 51}=P_{l}\left(V_{C 5}-V_{C 1}\right)
$$

The net work output is:

$$
W_{\text {net }}=W_{C 23}+W_{C 34}-W_{C 51}-W_{A B}
$$

Thermal efficiency can thus be given as:

$$
\eta_{t h}=\frac{W_{n e t}}{Q_{\text {in }}}=\frac{W_{C 23}+W_{C 34}-W_{C 51}-W_{A B}}{\left(Q_{B C 3}+Q_{C 34}\right)}
$$

If a regenerator is utilized to preheat the liquid before injection, then the heat saved can be given as:

$$
Q_{D E}=m\left[C_{p g}\left(T_{h}-T_{l}\right)\right] \approx m\left[h_{D}-h_{E}\right]
$$

And the improved thermal efficiency becomes:

$$
\eta_{t h}=\frac{W_{C 23}+W_{C 34}-W_{C 51}-W_{A B}}{\left(Q_{B C 3}+Q_{C 34}-Q_{D E}\right)}
$$

\subsection{Practical performance}

For real engines, the expansion process of the working fluid may not absorb sufficient heat to maintain isothermal expansion. The extent of isothermal behaviour achieved can be termed isothermality, $\gamma$, defined as the ratio of the actual work to the isothermal work [14],

$$
\gamma=W_{a c} / W_{i s o}
$$

Also in order to account for friction losses (that inevitably exists between piston and cylinder walls) and other thermodynamic losses, the efficiency terms: engine efficiency, $\eta_{e n}$, and pump efficiency, $\eta_{p u}$, can be taken into consideration. As such, the realistic net work of the cycle becomes:

$$
W_{\text {net }}=\eta_{e n}\left[W_{C 23}+\gamma W_{C 34}-W_{C 51}\right]-W_{A B} / \eta_{p u}
$$

Similarly, the realistic heat saved by the regenerator to preheat the feed liquid can be expressed in terms of the regenerator effectiveness, $\eta_{r e}$, to account for thermodynamic losses. 
Therefore, the realistic efficiency becomes:

$$
\eta_{t h}=\frac{\eta_{e n}\left[W_{C 23}+\gamma W_{C 34}-W_{C 51}\right]-W_{A B} / \eta_{p u}}{\left(Q_{B C 3}+Q_{C 34}-\eta_{r e} Q_{D E}\right)}
$$

\subsection{Effect of dead volume on engine performance}

With the aid of the pressure-specific volume (P-v) diagram in fig. 2, the operating maximum pressure achievable in the cylinder can be illustrated to depend on volume/mass of injected liquid, $m$, cylinder wall temperature, $T_{w}$, and cylinder dead volume $V_{d}$.

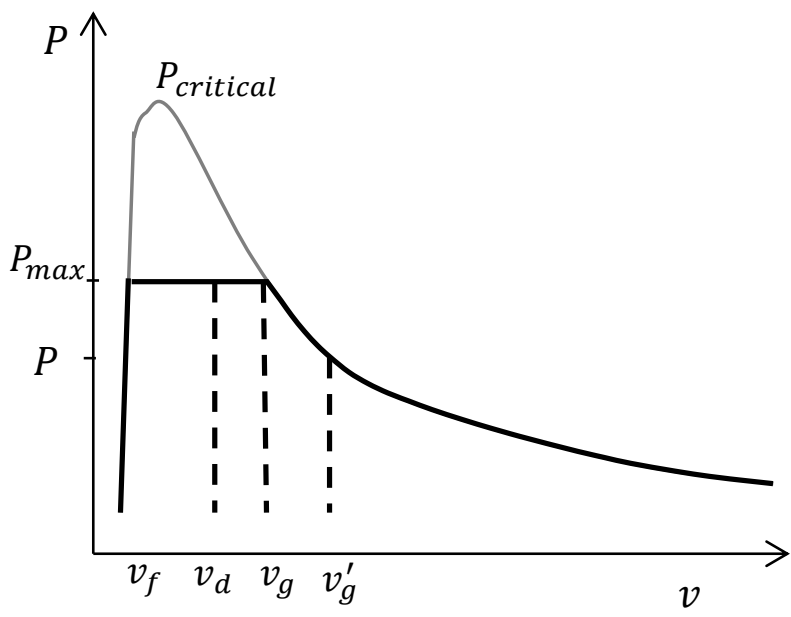

Fig. 2 P- $v$ diagram showing the effect of dead volume

Ideally, the maximum pressure achievable corresponds to the saturation pressure at the wall temperature $\left(P_{\max }=f\left(T_{w}\right)\right)$. And since the specific work transfer during the vaporization phase is given by $P_{\max }\left(v_{g}-v_{f}\right)$, it can be seen that for a given desired max pressure, to completely extract this work, the specific dead volume $v_{d}$ (ratio of the dead volume to mass of injected fluid) of the cylinder should be as little as the specific volume of the liquid $v_{f}$ at the desired pressure. This implies that the dead volume should be equal to the volume of injected liquid. In reality, this may not be the case. If the dead volume is slightly greater than the liquid volume, $v_{f}<v_{d}<v_{g}$, the max pressure will still be maintained, but the vaporization work will be reduced to $P_{\max }\left(v_{g}-v_{d}\right)$. If the dead volume is as large as the volume of the dry vapour, $v_{d}=v_{g}$, the fluid will be in the dry saturated vapour state, at the same max pressure, but no vaporization work can be extracted. Conversely, if $v_{d}>v_{g}$, the fluid will be in a saturated vapour state at a relatively lower pressure; and the pressure will no longer depend on $T_{w}$, but rather on the specific dead volume $\left(i e ., P=f\left(v_{d}\right)\right)$. In this case, no vaporization work is realized, and the achievable expansion work is relatively low since the pressure is reduced. 


\section{Organic working fluid comparison}

The selection of working fluid for RC is strongly correlated to the choice of the heat source, as the efficiency of the RC varies considerably with the thermodynamic properties of the working fluid employed [15]. Hence, in order to compare a reasonable number of working fluids, a pre-screening is carried out based on the two main thermodynamic parameters i.e. the evaporating and condensing temperature and pressure (depending on the available heat source and heat sink). The maximum evaporating temperature, $T_{\text {Evap }}$, is limited to $150^{\circ} \mathrm{C}$, while the minimum, $T_{\text {Cond }}$ is $30^{\circ} \mathrm{C}$. But if necessary, the minimum $T_{\text {Cond }}$ is raised to correspond to a minimum vapour pressure slightly above atmospheric pressure 1 bar (the permissible minimum pressure desired to avoid air infiltration issues).

With aid of the models outlined in section 2, analysis of the working fluids is carried out using Engineering Equation Solver (EES) [16]. The thermodynamic properties of the working fluids are computed directly in EES, using the built-in property functions. Given that a regenerator is employed, the regenerator effectiveness $\varepsilon_{r}$ is assumed to be 0.8 ; the pump and engine efficiencies are also both taken to be 0.8 .

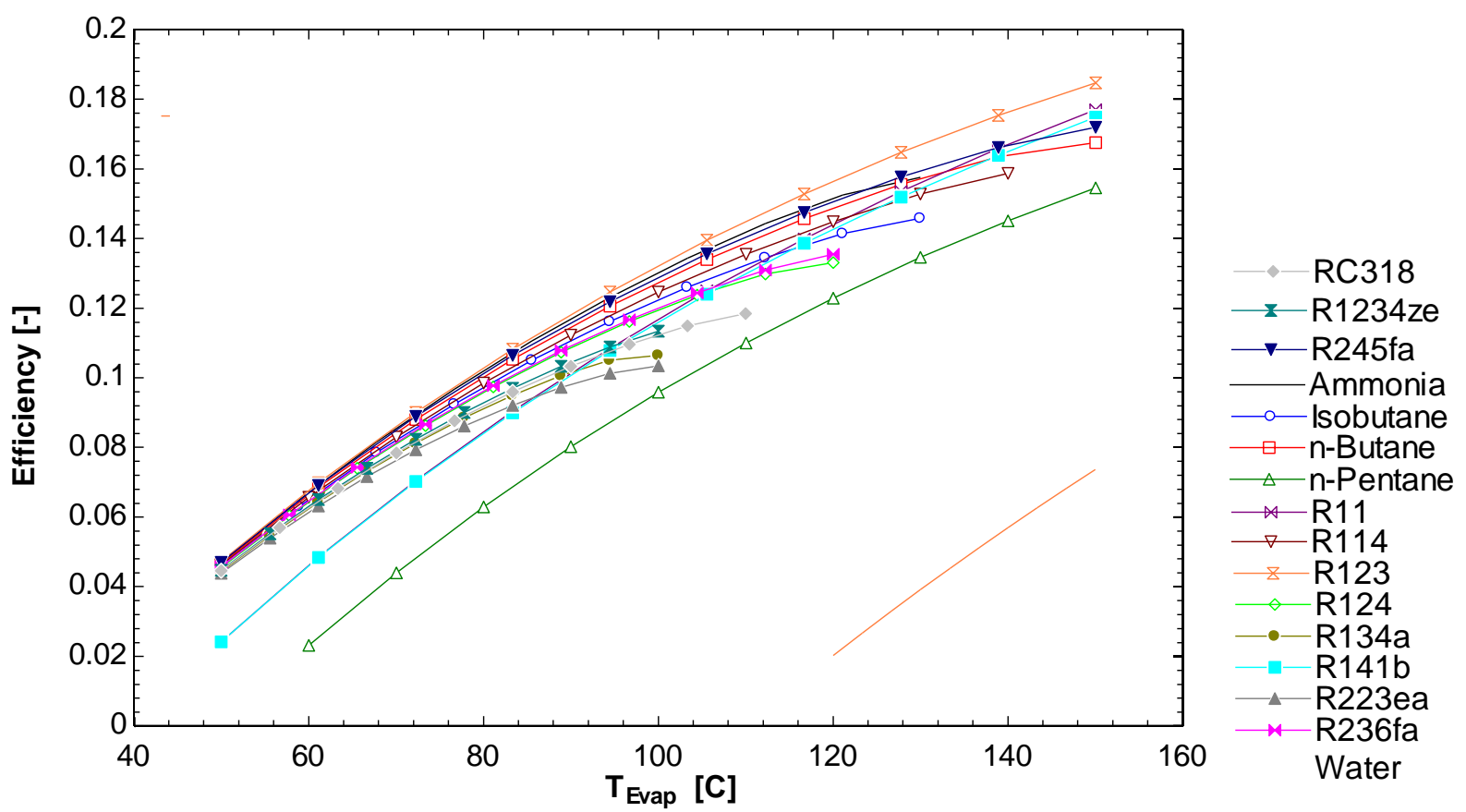

Fig. 3 Variation of efficiency with temperature for different working fluids

Sixteen working fluids were considered, and the variation of the thermal efficiency with evaporating temperature for the different working fluids is shown in fig. 3. Generally, the efficiency increases sharply with temperature, but the increase diminishes as the temperature approaches the critical temperature of the fluid. As can be seen from the figure, most of the fluids show very similar efficiencies at lower temperatures (below $70^{\circ} \mathrm{C}$ ). A comparison of the fluids parameters and performance at a reference evaporating temperature of $100^{\circ} \mathrm{C}$ is given in Table 1 . The maximum efficiency limit for the temperatures - Carnot efficiency, $\eta_{C n t},-$ is included for comparison. 
Table 1

Comparison of working fluids parameters and performance for isothermal ORC

\begin{tabular}{|c|c|c|c|c|c|c|c|c|c|c|c|}
\hline Substance & $\begin{array}{c}\boldsymbol{T}_{\text {Crit }} \\
{\left[{ }^{\circ} \mathrm{C}\right]}\end{array}$ & $\begin{array}{c}\boldsymbol{\rho} \\
{\left[\mathrm{kg} / \boldsymbol{m}^{\mathbf{3}}\right]}\end{array}$ & $\begin{array}{c}\boldsymbol{k} \\
{[\mathrm{W} / \mathrm{m} . \mathrm{K}]}\end{array}$ & $\begin{array}{l}T_{\text {Cond }} \\
{\left[{ }^{\circ} \mathrm{C}\right]}\end{array}$ & $\begin{array}{l}T_{\text {Evap }} \\
{\left[{ }^{\circ} \mathrm{C}\right]}\end{array}$ & $\begin{array}{l}P_{\text {Cond }} \\
\text { [bar] }\end{array}$ & $\begin{array}{l}\boldsymbol{P}_{\text {Evap }} \\
\text { [bar] }\end{array}$ & $\begin{array}{l}\mathrm{E} \\
{\left[\mathrm{kJ} / \boldsymbol{m}^{\mathbf{3}}\right]}\end{array}$ & $\begin{array}{c}\boldsymbol{\eta}_{\text {Cnt }} \\
{[\%]}\end{array}$ & $\begin{array}{l}\boldsymbol{\eta}_{t h} \\
{[\%]}\end{array}$ & $\begin{array}{l}\mathrm{V} \\
{\left[10^{-6} \mathrm{~m}^{3}\right]}\end{array}$ \\
\hline R11 & 198 & 7.915 & 0.0146 & 40 & 100 & 1.73 & 8.17 & 249 & 16.09 & 11.69 & 22.08 \\
\hline R114 & 145.7 & 14.33 & 0.0153 & 30 & 100 & 2.5 & 14.06 & 372 & 18.77 & 12.46 & 26.7 \\
\hline R123 & 183.7 & 5.53 & 0.0142 & 30 & 100 & 1.1 & 7.87 & 200 & 18.77 & 13.23 & 19.08 \\
\hline R124 & 122.3 & 20.74 & 0.0175 & 30 & 100 & 4.46 & 23.77 & 593 & 18.77 & 11.96 & 26.15 \\
\hline R245fa & 154 & 7.87 & 0.0199 & 30 & 100 & 1.77 & 12.69 & 310 & 18.77 & 12.9 & 19.16 \\
\hline R134a & 101 & 27.29 & 0.0194 & 30 & 100 & 7.71 & 39.75 & 854 & 18.77 & 10.64 & 26.92 \\
\hline R227ea & 102.8 & 30.91 & n.a & 30 & 100 & 5.27 & 28.27 & 606 & 18.77 & 10.34 & 37.78 \\
\hline R236fa & 124.9 & 16.45 & 0.0225 & 30 & 100 & 3.2 & 19.36 & 470 & 18.77 & 12.01 & 26.1 \\
\hline R1234ze & 109.4 & 22.76 & 0.0128 & 30 & 100 & 5.80 & 30.27 & 709 & 18.77 & 11.33 & 28.04 \\
\hline nPentane & 196.5 & 3.855 & 0.0221 & 50 & 100 & 1.6 & 5.9 & 194 & 13.41 & 9.58 & 33.42 \\
\hline nButane & 152 & 5.542 & 0.0250 & 30 & 100 & 2.84 & 15.26 & 413 & 18.77 & 12.75 & 23.7 \\
\hline Iso-Butane & 134.7 & 7.994 & 0.0257 & 30 & 100 & 4.05 & 19.84 & 528 & 18.77 & 12.25 & 27.88 \\
\hline HFE7000 & 164.6 & 7.96 & n.a & 40 & 100 & 1.20 & 6.62 & 186 & 16.09 & 11.15 & 31.2 \\
\hline $\mathrm{R} 141 \mathrm{~b}$ & 204.2 & 5.14 & 0.0141 & 40 & 100 & 1.33 & 6.77 & 202 & 16.09 & 11.61 & 21.01 \\
\hline Water & 374 & 0.743 & 0.029 & 110 & 150 & 1.43 & 4.76 & 169 & 9.46 & 7.37 & 4.61 \\
\hline RC318 & 115.2 & 24.85 & 0.0175 & 30 & 100 & 3.66 & 20.54 & 489 & 18.77 & 11.24 & 34.4 \\
\hline Ammonia & 132.3 & 6.77 & 0.0345 & 30 & 100 & 11.67 & 62.57 & 1612 & 18.77 & 13.03 & 7.06 \\
\hline
\end{tabular}

$\boldsymbol{\rho}$ and $\boldsymbol{k}$ are the density and thermal conductivity of the vapour at the end of expansion; E - Energy density - the amount of work output that can be obtained from a unit swept volume of engine size; V - liquid volume required for $1 \mathrm{~kJ}$ of work output 
The table indicates that R123 is the most efficient, followed by: ammonia, R245fa, n-Butane, R114, isobutane and R236fa, which all have good efficiencies of $>12 \%$. Amongst these fluids, R236fa, R114, and isobutane have high vapour densities and thermal conductivities, and as such have better potential to absorb heat during expansion. On the other hand, in terms of engine size, high saturation pressures result to higher energy density and smaller engine swept volumes. As such, ammonia and R134a (both having the highest operating pressures) exhibit the largest energy density and thus would require the smallest engine volume for a given amount of work output. Although, the small engine volume is desirable, excessive high operating pressures may exceed material or safety limits. R245fa, R114, n-Butane, R236fa and isobutane have modest pressures and show more than 1.5 times better energy density than R123. Conversely, besides water and ammonia, R123 and R245fa show relatively better pump size - with regards the volume of liquid required to deliver a $\mathrm{kJ}$ of work.

However, it should be noted that some substance contribute to global warming (GWP) and ozone layer depletion (ODP), owing to these negative effects on the environment, less harmful substances are preferred. R11and R114 (chlorofluorocarbons - CFCs) have high ODP and GWP and have already been banned under the Montreal protocol. R123 and R124 (hydrochlorofluorocarbons HCFCs) are in commercial use at present but has already been scheduled for phase out, while no phase out date is set for R245fa, R236fa, (hydrofluorocarbons - HFCs). Water, ammonia and the alkanes are environmentally friendly; however, alkanes are flammable and as such poses safety concerns. On the other hand, ammonia and R123 are toxic, while R245fa and R236fa are nonflammable and non-toxic. 


\section{Experiment}

Using R245fa as the working fluid, an experiment was carried out to assess the piston output force, the work output and thermal efficiency in relation to the quantity of injected liquid, in comparison to the ideal cycle.

\subsection{Test description}

The test engine (comprising the power cylinder, pump, condenser and the relevant accessories) was assembled as a closed cycle on aluminium strut profile as shown in fig. 4. The power cylinder was adapted from a commercial pneumatic cylinder (SMC95); the standard cylinder base was replaced with a bespoke aluminium base fitted with an injection nozzle, a pair of cartridge heaters, thermocouple (K type, accuracy $\pm 2.5^{\circ} \mathrm{C}$ ), and insulation pad. The electric heaters were employed to simulate solar or other thermal source, and the engine wall temperature was controlled with the aid of a PID temperature controller (XMT7100).

The condenser unit was fabricated as water cooled counter-flow helical coiled copper tube in flanged aluminium tube housing, fitted with a thermocouple and pressure gauge (accuracy class 2.5); and a liquid receiver affixed at the condenser exit. The cooling system was implemented by means of a $120 \mathrm{~mm}$ fan radiator (GTS120-LITE) and a 4 litre/min circulating pump.

The working fluid pump was assembled from a double acting $25 \mathrm{~mm}$ bore cylinder (SMC-C85) configured as a metering piston pump by means of two reversed non-return valves connected at the outlet port. This configuration employed standard parts to minimize build time and development cost. The choice of the piston pump enabled metering of very small volume of liquid $(<20 \mathrm{~mL})$, which could be driven pneumatically.

Before the experimentation, the complete assembled system was pressure tested with compressed air to check for leakages; and then evacuated (using a vacuum pump) to remove air and moisture. After which the unit was charged with the R245fa fluid to the required condenser pressure. The system parameters and operating conditions are listed in table 2.

Table 2

System parameters

\begin{tabular}{lc}
\hline Parameter & Value \\
\hline Cylinder Bore & $100 \mathrm{~mm}$ \\
Piston Stroke & $100 \mathrm{~mm}$ \\
Wall temperature & $90^{\circ} \mathrm{C}$ \\
Heating power & $300 \mathrm{~W}$ \\
Condenser temperature & $30^{\circ} \mathrm{C}$ \\
Condenser pressure & $1.78 \mathrm{bar}$ \\
Engine speed & $<200 \mathrm{~mm} / \mathrm{min}$ \\
\hline
\end{tabular}




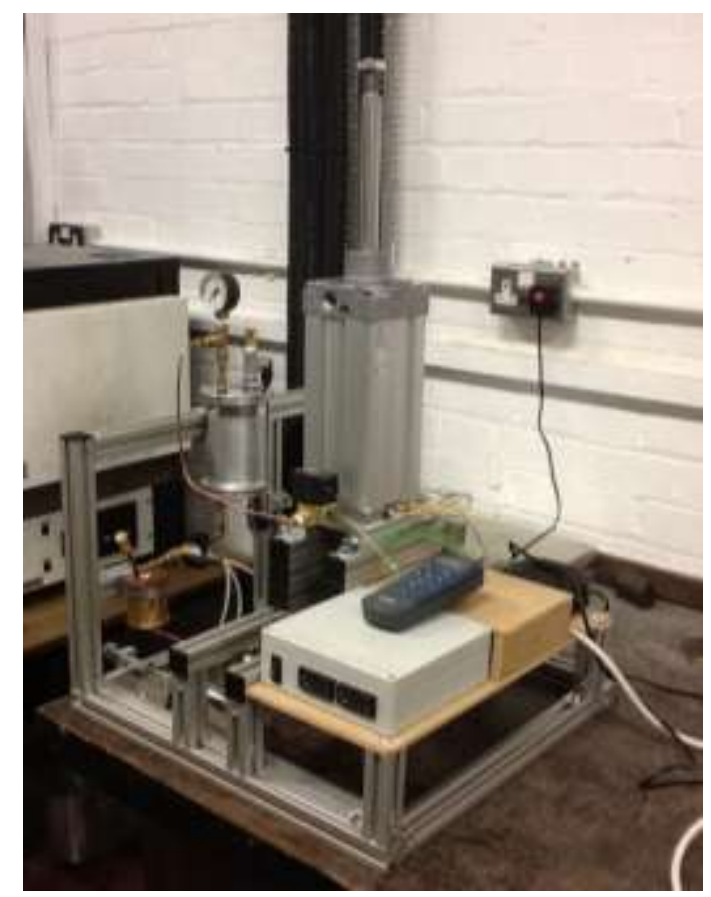

Fig. 4 the test engine for the isothermal ORC

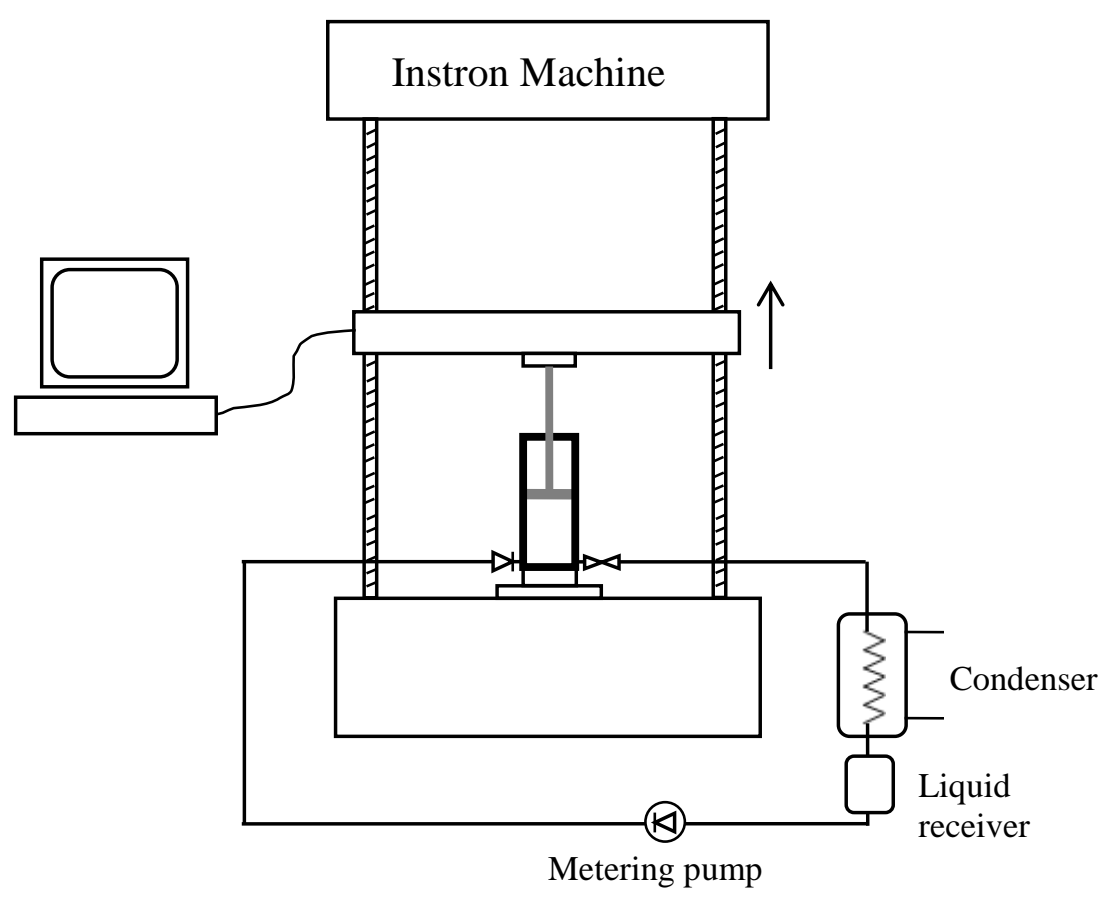

Fig. 5 Schematics of experimental set-up

Fig. 5 shows schematically the experimental set-up. The Instron machine (material testing machine, Instron ${ }^{\circledR} 5500 \mathrm{R}$ ) was employed to simulate a variable load with a controlled expansion speed. On operation, the metering pump injected the required volume of liquid into the heated cylinder. The resulting vapour expanded and pushed the piston against the load beam (incorporating a load cell) of the Instron machine; the resulting force (which is a measure of the vapour pressure) and piston displacement were recorded in the computer as the load beam retreated. Values of the force, pressure, and piston displacement were collected at various operating parameters, for analysis. 


\subsection{Results}

The results were taken, after heating the cylinder and making some runs to allow the system temperature to stabilize. The achieved $\mathrm{p}-\mathrm{V}$ diagram (for $9.5 \mathrm{~mL}$ injected liquid and $50 \mathrm{~mm} / \mathrm{min}$ piston speed) is shown in fig. 6 . The vaporization phase is clearly shown as the plateau on the curve evaporation pressure of 7.2 bar and a corresponding saturation temperature of $76.3^{\circ} \mathrm{C}$. The pressure corresponds to the difference between the pump's driving pneumatic pressure ( 9 bar) and the liquid pressure ( 2 bar) from the condenser. The extent of isothermal expansion achieved is shown in fig. 7 , for different piston speeds. On close inspection, it can be seen that the isothermality tends to slightly decrease with increase in speed. Nonetheless, isothermality of about 1 was achieved, i.e., the achieved expansion work equalled the expected isothermal work; thus implying that isothermal expansion was fully achieved.

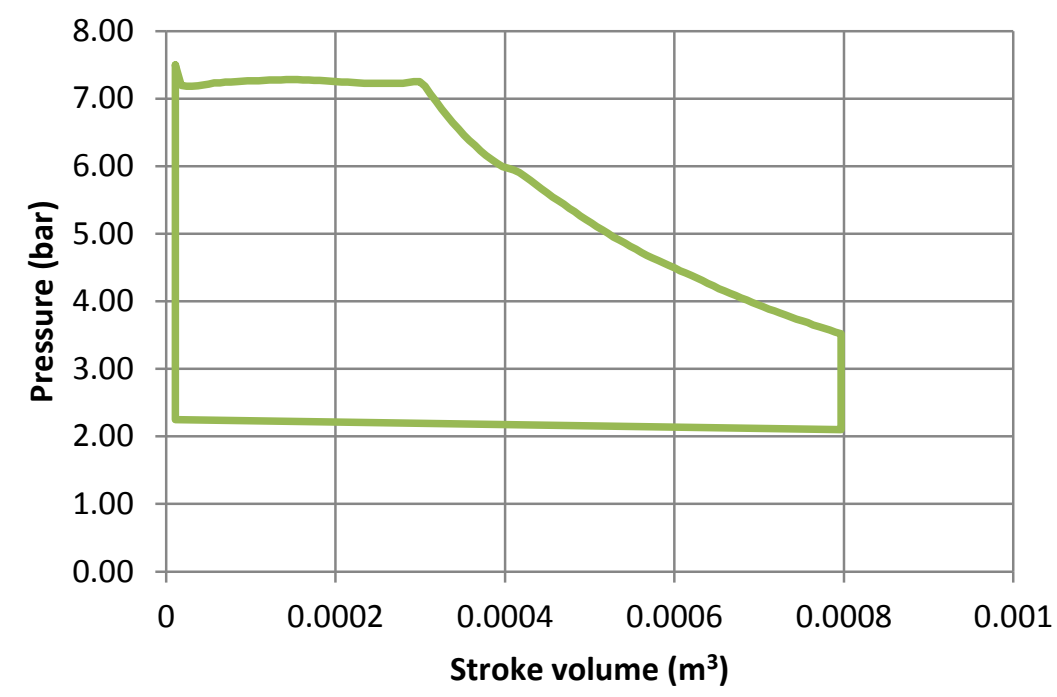

Fig. 6 Experimental P-V diagram

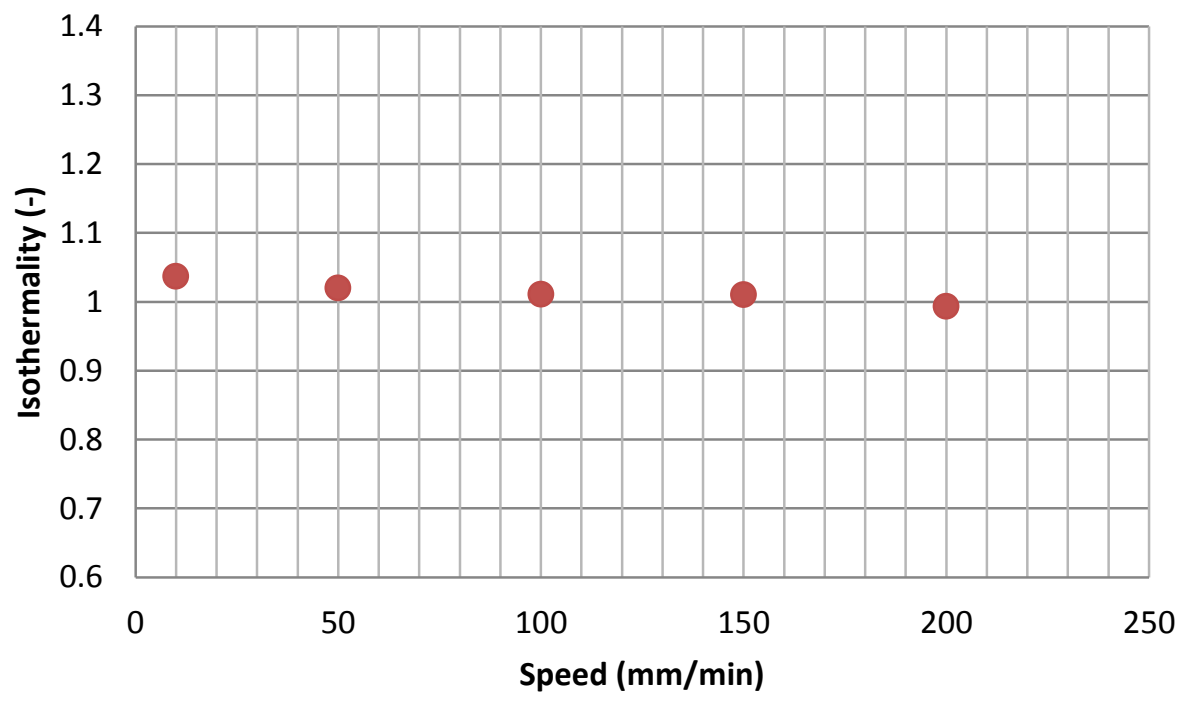

Fig. 7 Variation of isothermality with piston speed 


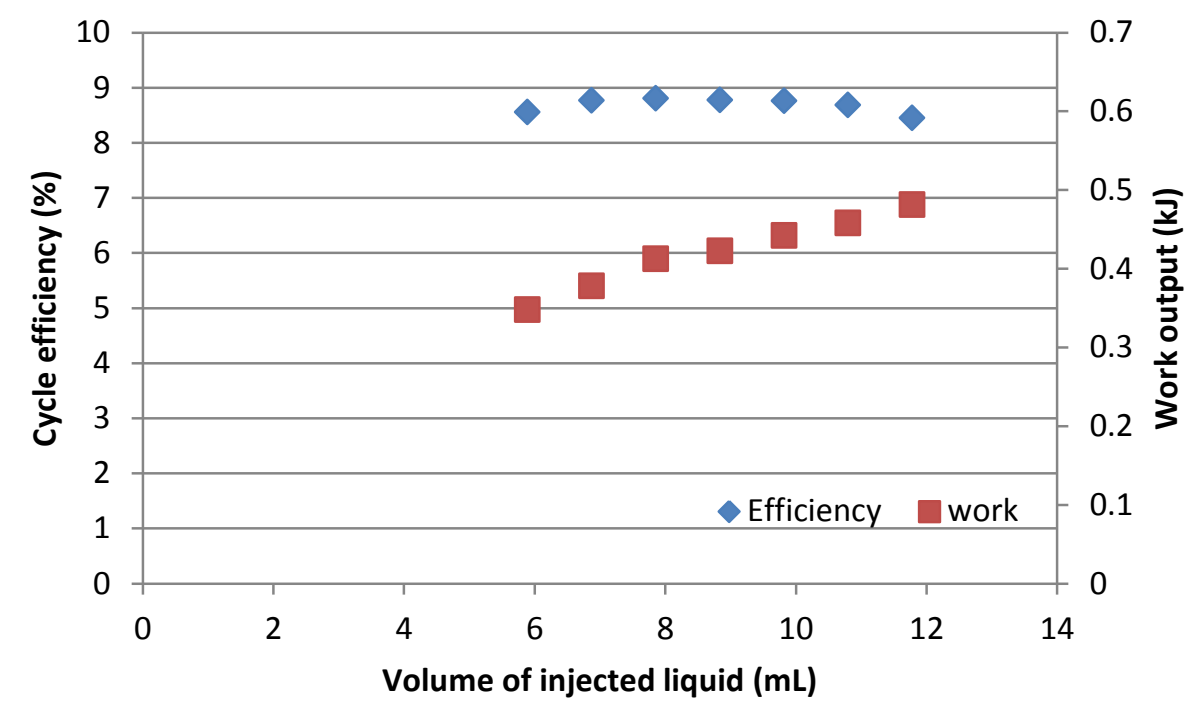

Fig. 8 Cycle efficiency and work vs. input liquid

Fig. 8 shows the variation of the cycle efficiency and work output achieved with the volume of injected liquid. As expected, the pressure at the end of stroke, and thus, the work output increases with increase in the quantity of injected liquid; $0.35-0.49 \mathrm{~kJ}$ of work was achieved for $6-12 \mathrm{~mL}$ of liquid input. However, the efficiency is seen to increase and then decrease slightly. High under-expansion losses (i.e., inadequate work extraction, due to the stroke length being too short relative to the increased pressure at the end of stroke) diminished the achieved performance as the liquid volume increases. Nevertheless, a maximum cycle efficiency of $8.8 \%$ was achieved (at $8 \mathrm{~mL}$ of input liquid), which closely matches the expected theoretical value of $9.2 \%$, and is more than a half of the Carnot efficiency (14.4\%) obtainable at the same evaporating and condensing temperatures. The achieved performance is better than the reported efficiency of about $5 \%$ for conventional ORC engines with same working fluid and at similar operating conditions [17,18]. Nevertheless the performance can be further improved by increasing the stroke length to extract more work and/or employing a regenerator to save on the heat input. 


\section{Application to desalination}

To investigate the potential performance of the engine (with R245fa working fluid) for desalination application, it is considered to ideally couple the engine to the previously described batch desalination system, DesaLink [12]. The system is depicted in fig. 9. On operation, the liquid injected into the power cylinder vaporizes, expands and drives the linkage mechanism at increasing mechanical advantage thus pressurizing a batch of saline water in the pump cylinder through the RO module where the salt is trapped while fresh water is permeated out. For high operating pressures, the other (rod) side of the cylinder could be connected to the condenser, so as to ease the return stroke.

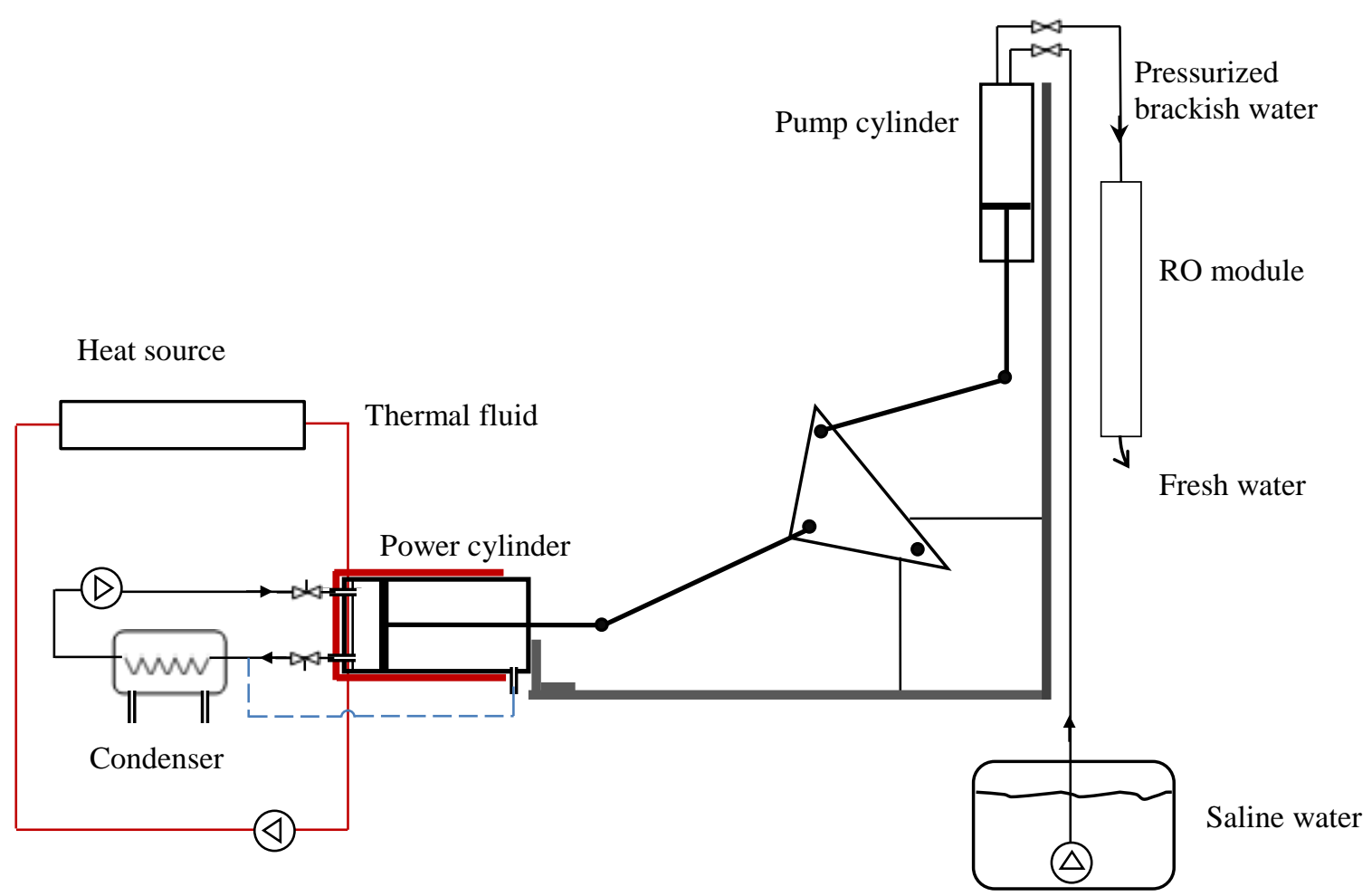

Fig. 9 System schematic

Table 3

DesaLink system parameters

Pump cylinder Power

cylinder

\begin{tabular}{lll} 
Cylinder diameter $(\mathrm{m})$ & 0.21 & 0.1 \\
Length of stroke $(\mathrm{m})$ & 0.35 & 0.228 \\
Volume of stroke $\left(\mathrm{m}^{3}\right)$ & 0.0031 & 0.008 \\
Initial Pressure (bar, abs) & 3.12 & 9 \\
Final Pressure (bar, abs) & 12.7 & 1.78 \\
Feed concentration $(\mathrm{ppm})$ & 4,000 & n.a. \\
\hline
\end{tabular}


The performance (operating requirements) of the engine can be analysed based on the DesaLink system parameters (table 3). Qiu et al [12] showed that for the operating parameters in table 3, the DesaLink produced fresh water output of 2.4 litres per cycle at cycle time of 4.5 mins and $70 \%$ recovery ratio from $4000 \mathrm{ppm}$ brackish water. Thus, based on the operating parameters in table 3 , it can be deduced that $3.1 \mathrm{~kJ}$ of work output $(\oint P d V)$, or initial and final driving pressures (net pressure across the piston) of 8 and 0.78 bar is required (at the power cylinder) to produce 2.4 litres of fresh water. Therefore, the working fluid (in the power cylinder) should deliver at least same amount of work or driving pressures, in order to achieve the same results.

Using EES in modelling and computing state properties; assuming a condenser temperature of $30^{\circ} \mathrm{C}$ and a corresponding pressure of 1.79 bar, the final pressure at stroke end is taken as 2.58 bar, while the starting pressure is 9.8 bar with a corresponding evaporating temperature of $88.8^{\circ} \mathrm{C}$. Consequently the required mass of fluid is obtained to be $0.095 \mathrm{~kg}$, and the heat input required to vaporize and maintain isothermal expansion is determined to be $21.4 \mathrm{~kJ}$ (assuming a regenerator is employed). Thus, for one cycle of operation, $0.095 \mathrm{~kg}$ ( $72 \mathrm{ml})$ of R245fa will be required to produce 2.4 litres of fresh water, at a thermal and mechanical SEC of $2.5 \mathrm{kWh} / \mathrm{m}^{3}$ and $0.36 \mathrm{kWh} / \mathrm{m}^{3}$ respectively. These are significantly improved values, compared to previously reported or predicted SECs (about 18 $\mathrm{kWh} / \mathrm{m}^{3}$ thermal and $0.8 \mathrm{kWh} / \mathrm{m}^{3}$ mechanical) for conventional ORC-RO desalination systems treating brackish water $[10,19,20]$. With regards to thermal requirements, $79 \mathrm{~W}$ of heat input will be needed to produce 32 litres of fresh water per hour. Assuming the heat is provided by a linear Fresnel reflector (LFR) solar collector with a collection efficiency of $35 \%$, under solar radiation of 4 $\mathrm{kWh} / \mathrm{m}^{2} /$ day, $0.44 \mathrm{~m}^{2}$ of land will be required to produce 256 litres of fresh water per $8 \mathrm{~h}$ day corresponding to an output of $582 \mathrm{l} / \mathrm{m}^{2} /$ day.

\section{Conclusion and further work}

ORC with isothermal expansion have been proposed and investigated for improved efficiency at low source temperatures. Various working fluids were analysed in terms of efficiency and engine size, for temperatures below $150{ }^{\circ} \mathrm{C}$. The analysis showed that R123 offers the best cycle efficiency amongst the fluids studied, but suffers the disadvantage of large engine swept volume. Ammonia and R245fa also offer good efficiencies, with ammonia having the most compact engine size but with detrimental high operating pressures.

Experimental investigation with R245fa showed that isothermal expansion was achieved for operating speed $<200 \mathrm{~mm} / \mathrm{min}$. Although the work output increases steadily with increase in the volume of injected liquid, the efficiency was impaired as a result of under expansion losses; nevertheless efficiency of $8.8 \%$ was realized.

Preliminary analysis of the engine's potential application to desalination (DesaLink) indicates that, with evaporating temperature of $90{ }^{\circ} \mathrm{C}$, fresh water output of 256 litres could be produced per $8 \mathrm{~h}$ per day, at a mechanical specific energy consumption of $0.36 \mathrm{kWh} / \mathrm{m}^{3}(1.3 \mathrm{~kJ} / \mathrm{litre})$. Nevertheless, further work and experimental analysis with the DesaLink machine will be required to verify its practicability. 


\section{Acknowledgement}

We acknowledge support from the School of Engineering and Applied Science, Aston University, in the form of a PhD scholarship for O. N. Igobo.

\section{References}

1. United Nations. The Millennium Development Goal Report, 2013.

http://www.undp.org/content/dam/undp/library/MDG/english/mdg-report-2013-english.pdf; accessed February 2014

2. F. Weert, J. Gun and J. Reckman. International groundwater resources assessment centre (igarc). Global overview of saline groundwater occurrence and genesis. Utrecht, July 2009

3. E. Mathioulakis, V. Belessiotis, E. Delyannis. Desalination by using alternative energy: review and state-of-the-art. Desalination, 203 (2007) 346-365.

4. P.A. Davies. A solar-powered reverse osmosis system for high recovery of freshwater from saline groundwater. Desalination, 271 (2011) $72-79$.

5. T.Y. Qiu and P.A. Davies. The scope to improve the efficiency of solar-powered reverse osmosis. Desalination and Water Treatment, 35 (2011) 14-32

6. D.P. Clarke, Y.M. Al-Abdeli, and G. Kothapalli. The effects of including intricacies in the modelling of a small-scale solar-PV reverse osmosis desalination system. Desalination 311 (2013) 127-136

7. A. Ghermandi and R. Messalem. Solar-driven desalination with reverse osmosis: the state of the art. Desalination and Water Treatment, 7 (2009) 285-296

8. D. Manolakos, G. Kosmadakis, S. Kyritsis, G. Papadakis. On site experimental evaluation of a low-temperature solar organic Rankine cycle system for RO desalination. Solar Energy, 83 (2009) 646-656

9. D. Manolakos, G. Papadakis, E. Mohamed, S. Kyritsis, K. Bouzianas. Design of an autonomous low-temperature solar Rankine cycle system for reverse osmosis desalination. Desalination 183 (2005) 73-80

10. J.C Bruno, J. Lo'pez-Villada, E. Letelier, S. Romera and A. Coronas. Modelling and optimisation of solar organic rankine cycle engines for reverse osmosis desalination. Applied Thermal Engineering 28 (2008) 2212-2226

11. C. Li, Y. Goswami, E. Stefanakos. Solar assisted sea water desalination: A review. Renewable and Sustainable Energy Reviews 19 (2013) 136-163

12. T.Y. Qiu, O.N. Igobo, P.A. Davies. DesaLink: solar powered desalination of brackish groundwater giving high output and high recovery. Desalination and Water Treatment, 51 (2013) 1279-1289 
13. O.N. Igobo and P.A. Davies. A high-efficiency solar Rankine engine with isothermal expansion. International Journal of Low-Carbon Technologies, 8 (2013) i27-i33

14. H. Chen, Y. Ding, Y. Li, X. Zhang, and C. Tan. Air fuelled zero emission road transportation: A comparative study. Applied Energy, 88 (2011) 337-342

15. B.F. Tchanche, G.Papadakis, G. Lambrinos, and A. Frangoudakis. Fluid selection for a lowtemperature solar organic Rankine cycle. Applied Thermal Engineering, 29 (2009) 24682476

16. S.A. Klein. Engineering Equation Solver, F-Chart Software. 2014

17. S.H. Kang. Design and experimental study of ORC (organic Rankine cycle) and radial turbine using R245fa working fluid. Energy 41 (2012) 514-524

18. S. Declaye, S. Quoilin, L. Guillaume, and V. Lemort. Experimental study on an open-drive scroll expander integrated into an ORC (Organic Rankine Cycle) system with R245fa as working fluid. Energy 55 (2013) 173-183

19. A.M. Delgado-Torresa, L. García-Rodríguez. Design recommendations for solar organic Rankine cycle (ORC)-powered reverse osmosis (RO) desalination. Renewable and Sustainable Energy Reviews 16 (2012) 44-53

20. J.J. Libert, and A. Maurel. "Desalination and renewable energies - a few recent developments." Desalination 39 (1981): 363-372. 